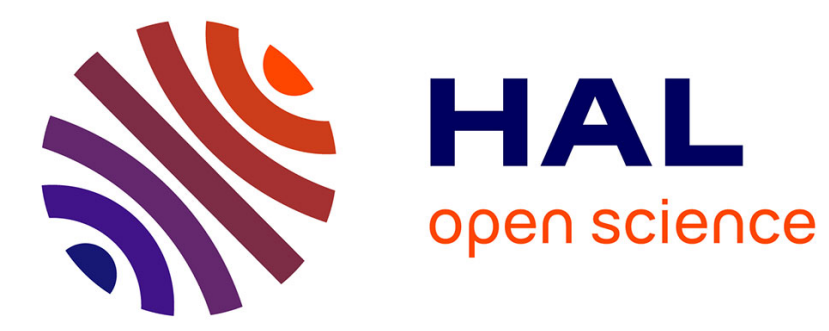

\title{
Targeting amino acids transporters (SLCs) to starve cancer cells to death
}

\author{
Yann Cormerais, Milica Vucetic, Jacques Pouysségur
}

\section{To cite this version:}

Yann Cormerais, Milica Vucetic, Jacques Pouysségur. Targeting amino acids transporters (SLCs) to starve cancer cells to death. Biochemical and Biophysical Research Communications, 2019, 520, pp.691 - 693. 10.1016/j.bbrc.2019.10.173 . hal-03488387

\section{HAL Id: hal-03488387 \\ https://hal.science/hal-03488387}

Submitted on 21 Dec 2021

HAL is a multi-disciplinary open access archive for the deposit and dissemination of scientific research documents, whether they are published or not. The documents may come from teaching and research institutions in France or abroad, or from public or private research centers.
L'archive ouverte pluridisciplinaire HAL, est destinée au dépôt et à la diffusion de documents scientifiques de niveau recherche, publiés ou non, émanant des établissements d'enseignement et de recherche français ou étrangers, des laboratoires publics ou privés.

\section{다)(1) $(5$}

Distributed under a Creative Commons Attribution - NonCommercial| 4.0 International 


\title{
Targeting amino acids transporters (SLCS) to starve cancer cells to death
}

\author{
Yann Cormerais ${ }^{1,2^{*}}$, Milica Vucetic $^{1^{*}}$, Jacques Pouysségur ${ }^{1,3 \#}$ \\ ${ }^{1}$ Department of Medical Biology, Centre Scientifique de Monaco (CSM), Monaco \\ ${ }^{2}$ Department of Genetics and Complex Diseases, Harvard Medical School, Boston, USA \\ ${ }^{3}$ University Côte d'Azur, (IRCAN), CNRS, INSERM, Centre A. Lacassagne, Nice, France
}

\section{* Both authors contributed equally \\ \# Corresponding author}

Nutrients, their capture, storage and metabolism are central for all forms of life providing energy and biomass $(1,2)$. The pioneer obsessive idea of Judah Folkman and others of blocking tumor nutrient access by preventing tumor vascular development finally was achieved with great success (3). However, the anti-angiogenic benefits for patients have been modest and in some cases worse as a result of increased hypoxia favoring increased cancer stem cells, tumor migration and metastasis (4). Therefore, with the same logic it was reasonable to think that blocking essential nutrient transporters, overexpressed in cancers, will not have the adverse effects of directly targeting the vasculature.

Among the different class of nutrients, amino acids (AAs) are obligatory for survival of any cell. In addition of being the building blocks of proteins, AA also act as essential metabolites in the biosynthesis lipids nucleotides and antioxidant defenses. Thus, fast growing tumor cells require an enhanced uptake of AAs to face the increased demand of exacerbated anabolism. To date, approximately thirty AA transporters have been described for mammalian cells, which are expressed in a tissue-specific manner (5). However, among them, only a small group transporters is consistently up regulated in a large range of different cancer types $(6,7)$. This, so-called 'minimal set of transporters', includes the L-type amino acid transporter 1 (LAT1, SLC7A5), alanine, serine, cysteine transporter 2 (ASCT2, SLC1A5), glutamate/cystine antiporter ( $\mathrm{xCT}$, SLC7A11), together with cell-surface antigen heavy chain (CD98, SLC3A2) that serves as chaperon for both LAT1 and XCT (8). In the last 5 years, through $S L C$ genetic disruption in aggressive cancer cell lines (colon, lung, pancreas), our group demonstrated the strong potential development of these AA transporters as anticancer targets (9-11).

\section{LAT1 is indispensable for EAA transport, general AA homeostasis and tumor growth}

LAT1 is a $\mathrm{Na}^{+}$-independent obligatory exchanger (stoichiometry 1:1) that promotes essential AA (EAA) uptake combined with glutamine efflux (12). Overexpression of LAT1 has been reported as a negative prognostic factor in a wide range of tumor types $(12,13)$. This global LAT1 overexpression pattern is explained by the fact that its expression is under control of 
numerous signaling pathways that are deregulated during carcinogenesis $(13,14)$. In 2016 we demonstrated that EAA transport activity of LAT1 is the key limiting step in cancer cell proliferation in vitro and in vivo by promoting EAA homeostasis and mTORC1 activity (11). Indeed, pharmacological inhibition or genetic disruption of LAT1 completely abolished leucine uptake, resulting in strong AA distress, and consequently, inhibition of mTORC1 and cell proliferation both in vitro and in vivo. These findings has been shown in six independent cell lines displaying different oncogenic mutations confirming the broad potential of targeting LAT1 for cancer therapy. Importantly, despite the existence of other EAA transporters in human physiology (i.e. SLC7a6-8, SLC43a1-2 and SLC6a14) (15), disruption of LAT1 activity revealed a lack of functional EAA transport redundancy. This study further increases the attractiveness of LAT1 as a therapeutic target and encourages continued development of specific inhibitors such as JPH2O3 (16). However, despite abolishing tumor growth, inhibition of LAT1 only displayed a cytostatic effect suggesting that this strategy alone would not be enough to obtain stable remission or cures in patients.

\section{ASCT2-driven glutamine uptake promotes tumor growth independently of LAT1 activity}

Following our line of research, we next investigated the role of another AA transporter, ASCT2. ASCT2 is a $\mathrm{Na}^{+}$-dependent transporter that exchanges small neutral AAs (Ala, Ser, Cys, GIn, and Asn - stoichiometry 1:1), and it has also been reported as a negative prognostic factor in multiple cancer types (17-20). ASCT2 has received a great interest in the last ten years as it has been described to be responsible for glutamine uptake in a large variety of cancer. Glutamine is a key metabolite required for anabolic growth of mammalian cells. Glutamine and its derivate glutamic acid are the obligate nitrogen donor during nucleotide and nonessential AA synthesis. Moreover, glutamine is used as carbon source in the mitochondria for the TCA cycle (anaplerosis). Precursors formed from glutamine are used for the synthesis of nucleotides, proteins, and lipids. In addition, a previous study proposed a model of functional coupling between ASCT2 and LAT1 by which ASCT2-driven glutamine export acts as a rate-limiting import for EAA by LAT1 (21). Therefore, according to these previous findings, we tested the hypothesis that targeting ASCT2 should have the dual advantage of starving cancer cells from both glutamine and EAA and therefore have a stronger therapeutic potential than targeting LAT1 alone. However, our results demonstrated that genetic disruption of ASCT2 in colon or lung adenocarcinoma cell lines neither affects LAT1 transport activity nor AA balance within the cell, suggesting that LAT1ASCT2 functional coupling is not general phenomenon across cancer types (21). Our findings corroborated a previous study showing that in osteosarcoma and triple negative breast cancer cell lines, glutamine uptake and cellular AA homeostasis could be achieved even in the absence of ASCT2 thanks to another set of $\mathrm{Na}^{+}$-dependent neutral AA transporter SNAT1/2 (SLC38A1/2) (22). Although presented data argue that ASCT2 function in the cancer cells is dispensable for LAT1 activity and AA homeostasis, important finding of this study showed that ASCT2 is yet promising target for anticancer therapy. Namely, ablation of ASCT2 reduced tumor growth in vivo through mechanisms that seem not to involve LAT1 
activity as no AA stress was observed in the ASCT2-KO tumor tissue analysis. These results suggest that targeting LAT1 and ASCT2 may have a synergistic effect and future efforts are required in order to uncover the true potential of these transporters as therapeutic targets.

\section{The cystine transporter $\mathrm{xCT}$, is critical for redox control, tumor growth and survival}

Our most recent study focused on the role of the cystine/glutamate exchanger XCT. System $\mathrm{XC}^{-}$is $\mathrm{Na}^{+}$-independent exchanger of oxidized form of cysteine (cystine, CySSCy) and glutamate. $x C T$-dependent uptake of cystine has been reported to be fundamental not only for AA homeostasis but also redox balance within the cell, as cysteine is rate-limiting step for synthesis of the most important non-enzymatic antioxidant - glutathione (GSH). Numerous studies consistently reported that $\mathrm{xCT}$ inhibition inevitably leads to GSH depletion and to a new form of cell death called ferroptosis (23) (Figure 1). In addition, increased expression of $\mathrm{xCT}$ has been connected to poor patient prognosis and increased resistance to chemotherapy (24). However, still somewhere neglected remained the fact that many of these results are obtained in in vitro conditions, under $21 \%$ of oxygen, where the only form of cysteine (CySH) present is cystine (CySSCy). This is a strong caveat as in an in vivo setting both oxidized and reduced forms exist interchangeably (25-27). In our study, we investigate importance of $\mathrm{xCT}$ transporter for cancer cell growth and survival both in vitro and in vivo, in one of the most aggressive tumor types - pancreatic ductal adenocarcinoma (PDAC). Our study demonstrated that genetic invalidation of $\mathrm{XCT}$ in vitro: 1 ) completely abolishes ${ }^{14} \mathrm{C}$-CySSCy uptake and consequently induces AA stress, suggesting that $\mathrm{xCT}$ is the major transporter of oxidized form of cysteine, 2) collapses intracellular GSH pool, 3) increases sensitivity of the cancer cells to the cytotoxic effects of the chemotherapeutics such as cisplatin and gemcitabine, and finally 4) is lethal in two independent PDAC cell lines, inducing ferroptotic-cell death (9). XCT-KO phenotype was reverted by $\mathrm{N}$-acetylcysteine, $\beta$-mercaptoethanol or $\mathrm{GSH}$. On the other side, vitamin $\mathrm{E}$ prevented lipid peroxide accumulation and ferroptosis, but did not restore AA balance in the xCT-KO cells.

The most intriguing result of our in vitro study is that despite the lethal phenotype of $x C T$ $\mathrm{KO}$, these cells were still capable to form tumor in vivo, although with a significant delay. Tumor-cell analysis suggested that in vivo reduced form of cysteine released, allowed survival and growth of XCT-KO cells in vivo. Recent reports of Wang and colleagues $(28,29)$ showed that fibroblast present in cancer stroma can uptake CySSCy, reduced and transfer it to the cancer cells upon chemotherapy challenge. Interestingly, this collaboration seems to be interrupted by $C D 8^{+} T$ cell secreting interferon- $\gamma$, which down-regulates expression of $x C T$ in fibroblasts and/or tumor cells through JAK-STAT1 signalling $(28,29)$. Conversely, it has been shown that inhibition of XCT increases sensitivity of tumor cells to immune therapy, most likely by increasing their antigenicity (30). These findings highlight $x C T$ as an $A A$ transporter of great potential for future anti-cancer therapy. 
In conclusion, our genetic approach provides a molecular basis pointing the key role of overexpressed LAT1, ASCT2 and XCT transporters in cancer cell homeostasis, growth, and survival. With the explosive knowledge of crystal structures of membrane transporter $(31,32)$, our optimism is great to see a rapid pharmacology development and therapeutic success in this area of cancer.

\section{References}

1. Palm W, Thompson CB. Nutrient acquisition strategies of mammalian cells. Nature 2017;546:234-42

2. Saxton RA, Sabatini DM. mTOR Signaling in Growth, Metabolism, and Disease. Cell 2017;169:361-71

3. Kerbel R, Folkman J. Clinical translation of angiogenesis inhibitors. Nature reviews Cancer 2002;2:727-39

4. Welti J, Loges S, Dimmeler S, Carmeliet P. Recent molecular discoveries in angiogenesis and antiangiogenic therapies in cancer. The Journal of clinical investigation 2013;123:3190-200

5. Kandasamy P, Gyimesi G, Kanai Y, Hediger MA. Amino acid transporters revisited: New views in health and disease. Trends in biochemical sciences 2018;43:752-89

6. Bhutia YD, Babu E, Ramachandran S, Ganapathy V. Amino Acid transporters in cancer and their relevance to "glutamine addiction": novel targets for the design of a new class of anticancer drugs. Cancer research 2015;75:1782-8

7. Broer A, Gauthier-Coles G, Rahimi F, van Geldermalsen M, Dorsch D, Wegener A, et al. Ablation of the ASCT2 (SLC1A5) gene encoding a neutral amino acid transporter reveals transporter plasticity and redundancy in cancer cells. The Journal of biological chemistry 2019;294:4012-26

8. Barretina J, Caponigro G, Stransky N, Venkatesan K, Margolin AA, Kim S, et al. The Cancer Cell Line Encyclopedia enables predictive modelling of anticancer drug sensitivity. Nature 2012;483:603-7

9. Daher B, Parks SK, Durivault J, Cormerais Y, Baidarjad H, Tambutte E, et al. Genetic Ablation of the Cystine Transporter XCT in PDAC Cells Inhibits mTORC1, Growth, Survival, and Tumor Formation via Nutrient and Oxidative Stresses. Cancer research 2019;79:3877-90

10. Cormerais Y, Massard PA, Vucetic M, Giuliano S, Tambutte E, Durivault J, et al. The glutamine transporter ASCT2 (SLC1A5) promotes tumor growth independently of the amino acid transporter LAT1 (SLC7A5). The Journal of biological chemistry 2018;293:2877-87

11. Cormerais Y, Giuliano S, LeFloch R, Front B, Durivault J, Tambutte E, et al. Genetic Disruption of the Multifunctional CD98/LAT1 Complex Demonstrates the Key Role of Essential Amino Acid Transport in the Control of mTORC1 and Tumor Growth. Cancer research 2016;76:4481-92

12. Yanagida O, Kanai Y, Chairoungdua A, Kim DK, Segawa H, Nii T, et al. Human L-type amino acid transporter 1 (LAT1): characterization of function and expression in tumor cell lines. Biochimica et biophysica acta 2001;1514:291-302 
13. Elorza A, Soro-Arnaiz I, Melendez-Rodriguez F, Rodriguez-Vaello V, Marsboom G, de Carcer $\mathrm{G}$, et al. HIF2alpha acts as an mTORC1 activator through the amino acid carrier SLC7A5. Molecular cell 2012;48:681-91

14. Hayashi $K$, Jutabha $P$, Endou $H$, Anzai N. c-Myc is crucial for the expression of LAT1 in MIA Paca-2 human pancreatic cancer cells. Oncology reports 2012;28:862-6

15. Broer $\mathrm{S}$, Palacin $\mathrm{M}$. The role of amino acid transporters in inherited and acquired diseases. The Biochemical journal 2011;436:193-211

16. Wempe MF, Rice PJ, Lightner JW, Jutabha P, Hayashi M, Anzai N, et al. Metabolism and pharmacokinetic studies of JPH203, an L-amino acid transporter 1 (LAT1) selective compound. Drug metabolism and pharmacokinetics 2012;27:155-61

17. Huang $\mathrm{F}$, Zhao $\mathrm{Y}$, Zhao J, Wu S, Jiang Y, Ma H, et al. Upregulated SLC1A5 promotes cell growth and survival in colorectal cancer. International journal of clinical and experimental pathology 2014;7:6006-14

18. Hassanein M, Hoeksema MD, Shiota M, Qian J, Harris BK, Chen H, et al. SLC1A5 mediates glutamine transport required for lung cancer cell growth and survival. Clinical cancer research : an official journal of the American Association for Cancer Research 2013;19:560-70

19. van Geldermalsen $M$, Wang $Q$, Nagarajah $R$, Marshall $A D$, Thoeng $A$, Gao D, et al. ASCT2/SLC1A5 controls glutamine uptake and tumour growth in triple-negative basal-like breast cancer. Oncogene 2016;35:3201-8

20. Broer A, Wagner C, Lang F, Broer S. Neutral amino acid transporter ASCT2 displays substrate-induced $\mathrm{Na}+$ exchange and a substrate-gated anion conductance. The Biochemical journal 2000;346 Pt 3:705-10

21. Nicklin $\mathrm{P}$, Bergman $\mathrm{P}$, Zhang B, Triantafellow $\mathrm{E}$, Wang $\mathrm{H}$, Nyfeler $\mathrm{B}$, et al. Bidirectional transport of amino acids regulates mTOR and autophagy. Cell 2009;136:521-34

22. Broer A, Rahimi F, Broer S. Deletion of Amino Acid Transporter ASCT2 (SLC1A5) Reveals an Essential Role for Transporters SNAT1 (SLC38A1) and SNAT2 (SLC38A2) to Sustain Glutaminolysis in Cancer Cells. The Journal of biological chemistry 2016;291:13194-205

23. Dixon SJ, Lemberg KM, Lamprecht MR, Skouta R, Zaitsev EM, Gleason CE, et al. Ferroptosis: an iron-dependent form of nonapoptotic cell death. Cell 2012;149:106072

24. Koppula $P$, Zhang $Y$, Zhuang L, Gan B. Amino acid transporter SLC7A11/xCT at the crossroads of regulating redox homeostasis and nutrient dependency of cancer. Cancer Commun (Lond) 2018;38:12

25. Zhang W, Trachootham D, Liu J, Chen G, Pelicano H, Garcia-Prieto C, et al. Stromal control of cystine metabolism promotes cancer cell survival in chronic lymphocytic leukaemia. Nat Cell Biol 2012;14:276-86

26. Droge $\mathrm{W}$, Kinscherf R. Aberrant insulin receptor signaling and amino acid homeostasis as a major cause of oxidative stress in aging. Antioxid Redox Signal 2008;10:661-78

27. Brigham MP, Stein WH, Moore S. The Concentrations of Cysteine and Cystine in Human Blood Plasma. J Clin Invest 1960;39:1633-8

28. Wang W, Green M, Choi JE, Gijon M, Kennedy PD, Johnson JK, et al. CD8(+) T cells regulate tumour ferroptosis during cancer immunotherapy. Nature 2019;569:270-4

29. Wang W, Kryczek I, Dostal L, Lin H, Tan L, Zhao L, et al. Effector T Cells Abrogate Stroma-Mediated Chemoresistance in Ovarian Cancer. Cell 2016;165:1092-105 
30. Arensman MD, Yang XS, Leahy DM, Toral-Barza L, Mileski M, Rosfjord EC, et al. Cystine-glutamate antiporter XCT deficiency suppresses tumor growth while preserving antitumor immunity. Proceedings of the National Academy of Sciences of the United States of America 2019;116:9533-42

31. Yan R, Zhao X, Lei J, Zhou Q. Structure of the human LAT1-4F2hc heteromeric amino acid transporter complex. Nature 2019;568:127-30

32. Errasti-Murugarren E, Fort J, Bartoccioni P, Diaz L, Pardon E, Carpena X, et al. L amino acid transporter structure and molecular bases for the asymmetry of substrate interaction. Nature communications 2019;10:1807

\section{Cystine/Glutamate transporter (xCT) and induction of "FERROPTOSIS"}

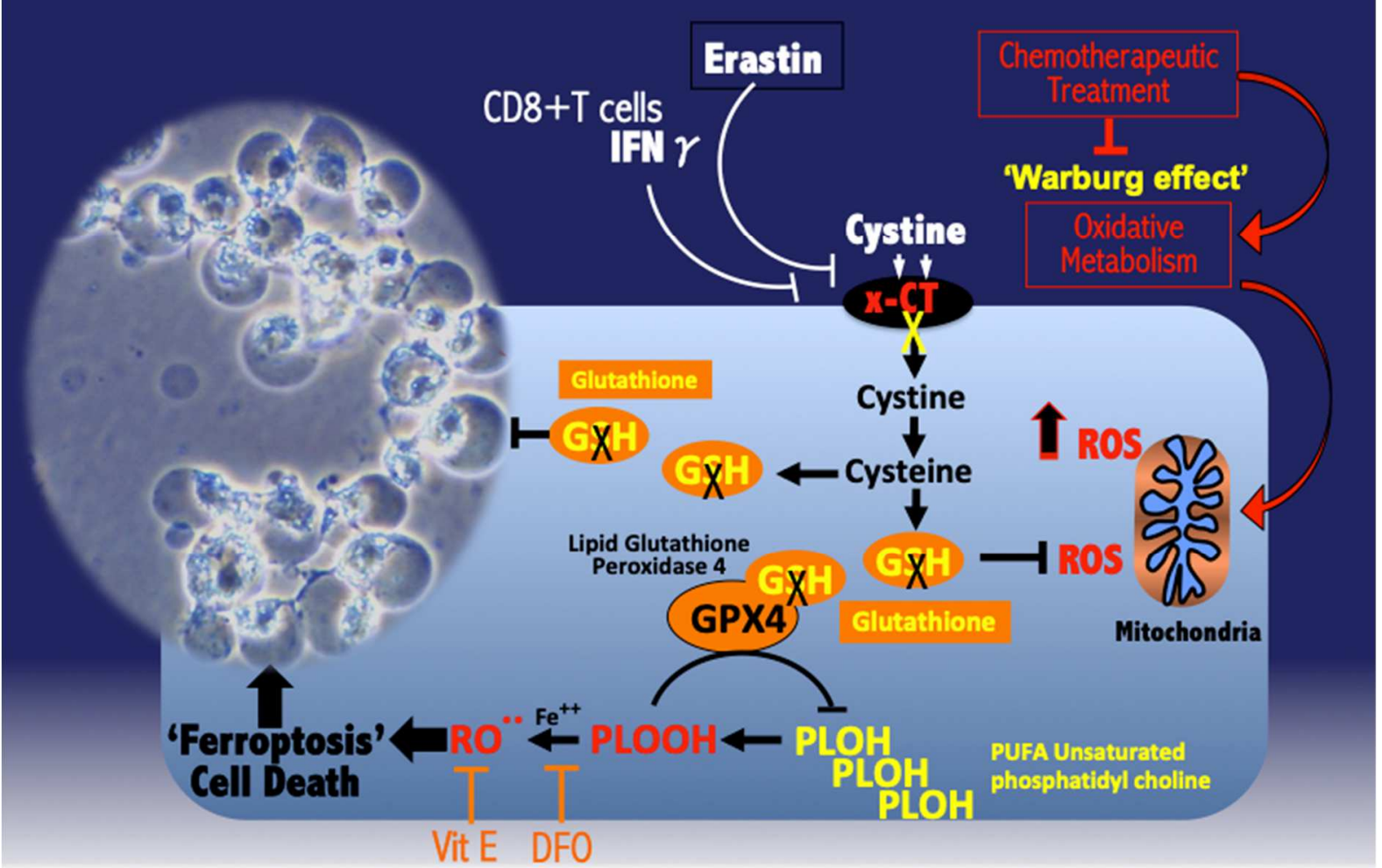

Figure 1: Genetic ablation of the Cystine/Glutamate Transporter XCT in PDAC cell lines, inhibits mTORC1, growth, survival and tumor formation. WT phenotype is restored by $\mathrm{N}$ acetyl cysteine (NAC), or Glutathione (GSH). 1 $1 \mu \mathrm{M}$ Erastin mimics xCT-KO cells inducing Ferrotoptic cell death. (refs 9, 23, 28) 